\title{
Concurrent Newborn Hearing and Genetic Screening in a Multi-Ethnic Population in South China
}

\author{
Xiangrong Tang ${ }^{1 *}$, Lihua Liu ${ }^{1}$, Sulan Liang ${ }^{1}$, Meie Liang ${ }^{1}$, Tao Liao ${ }^{2}$, Shiqiang Luo ${ }^{3}$, \\ Tizhen Yan ${ }^{3 *}$ and Jianping Chen ${ }^{4 *}$ \\ ${ }^{1}$ Department of Otolaryngology-Head and Neck Surgery, Liuzhou Maternal and Child Health Care Hospital, Liuzhou, China, \\ ${ }^{2}$ Department of Obstetrics, Liuzhou Maternal and Child Health Care Hospital, Liuzhou, China, ${ }^{3}$ Department of Medical \\ Genetics, Liuzhou Maternal and Child Health Care Hospital, Liuzhou, China, ${ }^{4}$ Department of Children's Health Care, Liuzhou \\ Maternal and Child Health Care Hospital, Liuzhou, China
}

\section{OPEN ACCESS}

Edited by:

Zhengqing $\mathrm{Hu}$,

Wayne State University, United States

Reviewed by:

Guanglin $\mathrm{He}$,

Nanyang Technological University, Singapore

Hui Jiang,

Fudan University, China

*Correspondence:

Xiangrong Tang

txrong.happy@163.com

Tizhen Yan

439078813@qq.com

Jianping Chen

chenjp1975@sina.com

Specialty section:

This article was submitted to

Pediatric Otolaryngology,

a section of the journal

Frontiers in Pediatrics

Received: 21 July 2021 Accepted: 03 November 2021 Published: 30 November 2021

Citation:

Tang X, Liu L, Liang S, Liang M, Liao T, Luo S, Yan T and Chen J (2021) Concurrent Newborn Hearing and Genetic Screening in a Multi-Ethnic Population in South China. Front. Pediatr. 9:734300. doi: 10.3389/fped.2021.734300
Hearing loss is a common sensory deficit in humans with intricate genomic landscape and mutational signature. Approximately 1-3 out of 1,000 newborns have hearing loss and up to $60 \%$ of these cases have a genetic etiology. In this study, we conducted the concurrent newborn hearing and genetic screening in 20 mutations (18 pathogenic variants in GJB2, SLC26A4, and MT-RNR1 and 2 uncertain clinical significance variants in GJB3) for 9,506 normal newborns (4,977 [52.4\%] males) from 22 ethnic population in South China. A total of $1,079(11.4 \%)$ newborns failed to pass the initial hearing screening; 160 (1.7\%) infants failed to pass the re-screening, and $135(1.4 \%)$ infants presented the diagnostic hearing loss. For the genetic screening, $220(2.3 \%)$ newborns who presented at least one of the screened mutations were more likely to fail the hearing screening and have diagnostic hearing loss than mutation-negative newborns. In comparison to the differences of distribution of mutations, we did not identify any significant difference in the prevalence of screened mutations between Han group ( $n=$ $5,265)$ and Zhuang group ( $n=3,464)$, despite the lack of number of minority ethnic groups. Studies including larger number of minority ethnic populations are needed in the future.

Keywords: newborn, hearing loss, hearing screening, limited genetic screening, multi-ethnic population

\section{INTRODUCTION}

Hearing loss is a common sensory deficit in humans; it occurs in an estimated $10 \%$ of the world's population (500 million individuals) (http://www.who.int/deafness/en/) and affects infants' speech acquisition and cognitive, social, and emotional development $(1,2)$. Approximately $1-3$ out of 1,000 newborns have the hearing loss significant enough to affect speech and language development and up to $60 \%$ of these cases have a genetic etiology (3). In addition, hearing loss is one of the most etiologically heterogeneous disorders (4). To date, more than 6,000 mutations in more than 150 genes were proposed to be associated with hearing loss (5).

Early diagnosis and intervention have been shown to be effective in facilitating speech and language development in hearing loss infants and children (6). As a result, the universal newborn hearing screening (UNHS) is now mandated throughout many countries around the world (79). However, conventional UNHS is concerned about the missed detection of mild hearing loss, later-onset or drug-induced hearing loss (10); therefore, the targeted genetic pathogenic variants screening should be considered in the UNHS $(3,11)$. 
Nevertheless, it is widely accepted that differential genetic architectures exist between populations (12). Due to the intricate genomic landscape and mutational signature of hearing loss associated genes, it is necessary to consider the ethnic variation when applying targeted variant panels more widely for the screening of newborn hearing loss $(13,14)$. For instance, although the GJB2 c.35delG variant is common in Western Europeans, its prevalence is negligible across China and Southeast Asia (15). China has 56 different ethnic groups with apparent genetic differences (the Han group and 55 ethnic minorities) $(16,17)$; however, few studies reported hearing lossassociated genetic epidemiological differences among various Chinese ethnic groups (18-20).

Guangxi province located in the southwest China has the greatest population of ethnic minorities, including more than 20 groups. Among them, the Zhuang group accounts for about one-third of the total population, which is the largest ethnic minority group in China (http://www.stats.gov.cn/). In this study of concurrent hearing and genetic newborn screening, for the first time, we reported the distributions and characteristics of 20 hearing-loss-related genetic variants in 9,506 newborns from 22 different ethnic groups in Guangxi province.

\section{METHODS}

\section{Study Population and Procedure}

This study included a total of 9,506 normal newborns (non-intensive care unit newborns) in Liuzhou Maternal and Child Health Hospital, who received the concurrent hearing and genetic screening from July 2018 to March 2020. The information of ethnicity was collected from the household certificate. Newborn hearing screening and collection of blood spot specimens for genetic screening were conducted after birth as inpatients. Families were notified via the clinical report of screening results, and the genetic counseling was offered to those with any genetic mutation. The overall flowchart of screening procedure is shown in Figure 1.

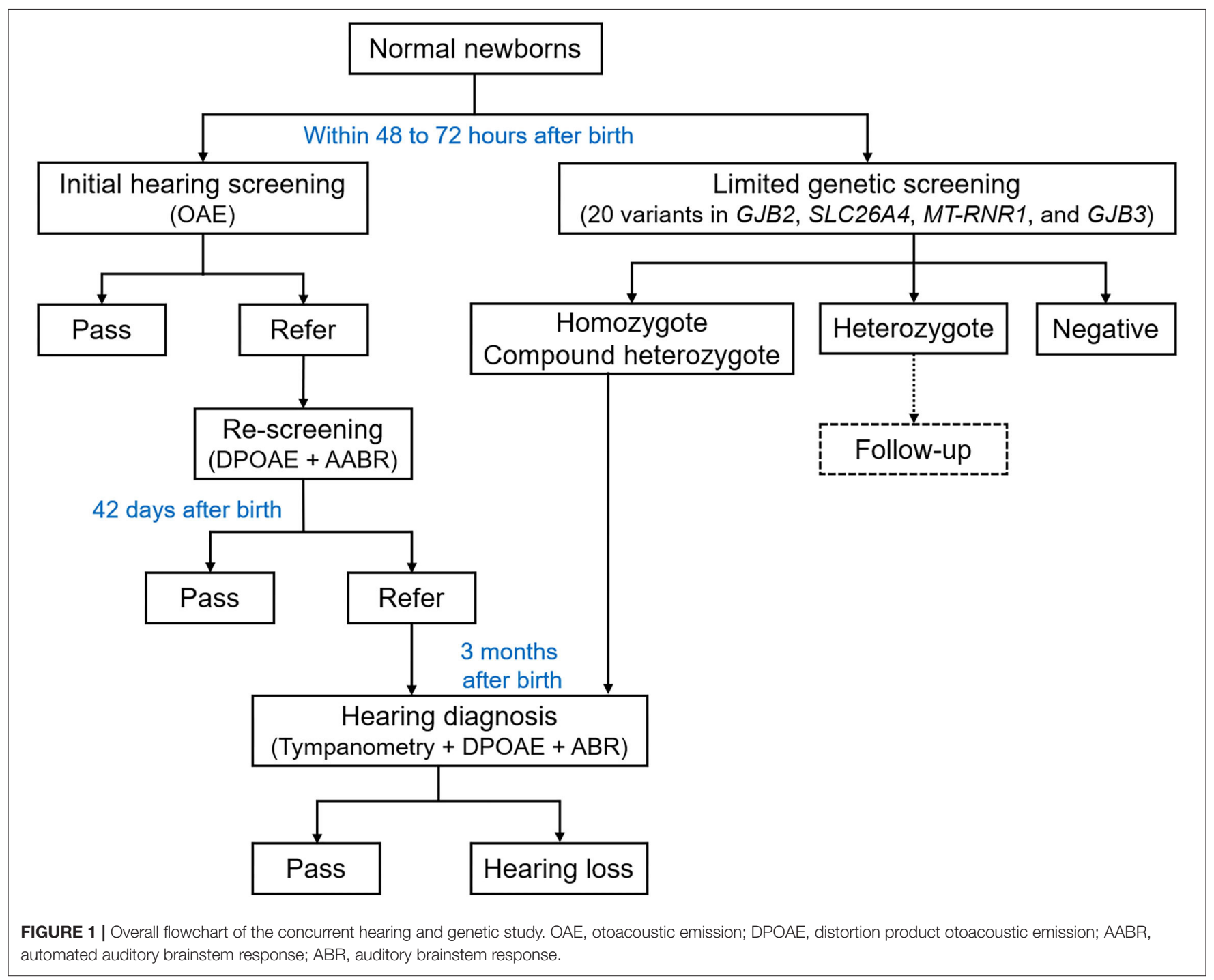


TABLE 1 | Overall results of concurrent hearing and genetic screening.

\begin{tabular}{|c|c|c|c|c|}
\hline Hearing outcomes & Mutation negative $(n=9,286)$ & Mutation positive $(n=220)$ & $\chi^{2}$ & $p$ \\
\hline Initial screening & & & 5.624 & 0.018 \\
\hline Pass, $n(\%)$ & $8,243(88.8)$ & $184(83.6)$ & & \\
\hline Refer, $n(\%)$ & $1,043(11.2)$ & $36(16.4)$ & & \\
\hline${ }^{\mathrm{a}}$ Re-screening & & & 7.294 & 0.007 \\
\hline Pass, $n(\%)$ & $894(85.7)$ & $25(69.4)$ & & \\
\hline No, $n(\%)$ & $9,158(98.6)$ & $213(96.8)$ & & \\
\hline Yes, $n(\%)$ & $128(1.4)$ & $7(3.2)$ & & \\
\hline
\end{tabular}

${ }^{a} A$ total number of 1,079 newborns failed to pass the initial screening and underwent the re-screening.

TABLE 2 | Results of screening in 21 different ethnic groups.

\begin{tabular}{|c|c|c|c|c|c|}
\hline Ethnic groups & Population number & Mutation carrier, $\boldsymbol{n}(\%)$ & Initial screening refer, $\boldsymbol{n}(\%)$ & Re-screening refer, $n(\%)$ & Hearing loss, $n(\%)$ \\
\hline Han & 5,265 & $130(2.5)$ & 575 (10.9) & $75(1.4)$ & $66(1.3)$ \\
\hline Zhuang & 3,464 & $72(2.1)$ & $413(11.9)$ & $68(2.0)$ & $56(1.6)$ \\
\hline Miao & 184 & $3(1.6)$ & $26(14.1)$ & $5(2.7)$ & $4(2.2)$ \\
\hline Dong & 183 & $4(2.2)$ & 24 (13.1) & $6(3.3)$ & $4(2.2)$ \\
\hline Maonan & 14 & $1(7.1)$ & $1(7.1)$ & 0 & 0 \\
\hline Shui & 10 & 0 & $4(40.0)$ & 0 & 0 \\
\hline Buyi & 7 & 0 & 0 & 0 & 0 \\
\hline Tujia & 6 & $1(16.7)$ & 0 & 0 & 0 \\
\hline Manchu & 5 & 0 & 0 & 0 & 0 \\
\hline $\mathrm{Li}$ & 3 & 0 & $1(33.3)$ & 0 & 0 \\
\hline Yi & 3 & 0 & 0 & 0 & 0 \\
\hline Dai & 2 & 0 & 0 & 0 & 0 \\
\hline Jing & 1 & 0 & 0 & 0 & 0 \\
\hline She & 1 & 0 & 0 & 0 & 0 \\
\hline Naxi & 1 & 0 & 0 & 0 & 0 \\
\hline Korean & 1 & 0 & 0 & 0 & 0 \\
\hline Total & 9,506 & 220 (2.3) & $1,079(11.4)$ & $160(1.7)$ & $137(1.4)$ \\
\hline
\end{tabular}

This study was reviewed and approved by the Ethics Committee of Liuzhou Maternal and Child Health Care Hospital (NO. 2018-049). All parents of newborns gave written informed consent in accordance with the Declaration of Helsinki.

\section{Newborn Hearing Screening}

As described previously (9), the newborn initial hearing screening was conducted within $48-72 \mathrm{~h}$ after birth. The otoacoustic emission (OAE) test was performed by the trained nurse using the AccuScreen hearing-screening Instrument (Denmark, Otometrics) in a quiet room under background noise lower than $40 \mathrm{~dB}(\mathrm{~A})$. Newborns who failed to pass the initial screening were referred for re-screening around 42 days after birth using the distortion product otoacoustic emission (DPOAE) and automated auditory brainstem response (AABR) test. Newborns who failed to pass the re-screening were referred to the diagnostic DPOAE and ABR tests conducted by audiological technicians around 3 months after birth. The ABR test was performed using the ICS ChartrEP200 auditory evoked potentials workshop (Denmark, Otometrics).

\section{Limited Genetic Screening}

The genomic DNA was extracted from dried blood spot specimens and genotyped using the Genetic Testing Kit 
TABLE 3 | Distribution of hearing loss associated mutations in different ethnic groups.

\begin{tabular}{|c|c|c|c|c|c|c|c|c|c|}
\hline Mutant genotypes, $n$ (\%) & $\begin{array}{c}\text { Han } \\
(n=5,265)\end{array}$ & $\begin{array}{c}\text { Zhuang } \\
(n=3,464)\end{array}$ & $\begin{array}{c}\text { Yao } \\
(n=220)\end{array}$ & $\begin{array}{c}\text { Miao } \\
(n=184)\end{array}$ & $\begin{array}{c}\text { Dong } \\
(n=183)\end{array}$ & $\begin{array}{c}\text { Mulao } \\
(n=108)\end{array}$ & $\begin{array}{l}\text { Maonan } \\
(n=14)\end{array}$ & $\begin{array}{c}\text { Tujia } \\
(n=6)\end{array}$ & $\begin{array}{c}\text { Gelao } \\
(n=3)\end{array}$ \\
\hline GJB2 (NM_004004.5) & $61(1.2)$ & $29(0.8)$ & $2(0.9)$ & $2(1.1)$ & $3(1.6)$ & $4(3.7)$ & 0 & 0 & $1(33.3)$ \\
\hline c.235de1C/- & $46(0.9)$ & $24(0.7)$ & $1(0.4)$ & $2(1.1)$ & $3(1.6)$ & $3(2.8)$ & 0 & 0 & $1(33.3)$ \\
\hline c.299_300de1AT/- & $13(0.3)$ & $3(0.1)$ & $1(0.4)$ & 0 & 0 & $1(0.9)$ & 0 & 0 & 0 \\
\hline c.176_191del16/- & $2(0.04)$ & $2(0.06)$ & 0 & 0 & 0 & 0 & 0 & 0 & 0 \\
\hline GJB3 (NM_024009.3) & $4(0.08)$ & $1(0.03)$ & 0 & 0 & 0 & 0 & 0 & 0 & 0 \\
\hline c. $538 \mathrm{C}>\mathrm{T} /-$ & $2(0.04)$ & 0 & 0 & 0 & 0 & 0 & 0 & 0 & 0 \\
\hline c. $547 \mathrm{G}>\mathrm{A} /-$ & $2(0.04)$ & $1(0.03)$ & 0 & 0 & 0 & 0 & 0 & 0 & 0 \\
\hline SLC26A4 (NM_000441.2) & $60(1.1)$ & $37(1.1)$ & $2(0.9)$ & $1(0.5)$ & $1(0.6)$ & 0 & 0 & 0 & 0 \\
\hline c.919-2A>G /- & $30(0.6)$ & $16(0.5)$ & 0 & 0 & $1(0.6)$ & 0 & 0 & 0 & 0 \\
\hline c. $1229 \mathrm{C}>\mathrm{T} /-$ & $7(0.1)$ & $11(0.3)$ & $1(0.4)$ & $1(0.5)$ & 0 & 0 & 0 & 0 & 0 \\
\hline c.754T>C/- & $6(0.1)$ & $6(0.2)$ & $1(0.4)$ & 0 & 0 & 0 & 0 & 0 & 0 \\
\hline c. $1707+5 \mathrm{G}>\mathrm{A} /-$ & $4(0.08)$ & 0 & 0 & 0 & 0 & 0 & 0 & 0 & 0 \\
\hline c. 2168 A > G/- & $4(0.08)$ & 0 & 0 & 0 & 0 & 0 & 0 & 0 & 0 \\
\hline c. $1975 G$ > C/- & $2(0.04)$ & $2(0.06)$ & 0 & 0 & 0 & 0 & 0 & 0 & 0 \\
\hline C. $1174 \mathrm{~A}>\mathrm{T} /-$ & $2(0.04)$ & $1(0.03)$ & 0 & 0 & 0 & 0 & 0 & 0 & 0 \\
\hline c. $1226 \mathrm{G}>\mathrm{A} /-$ & $1(0.02)$ & 0 & 0 & 0 & 0 & 0 & 0 & 0 & 0 \\
\hline c. $2162 \mathrm{C}>\mathrm{T} /-$ & $1(0.02)$ & 0 & 0 & 0 & 0 & 0 & 0 & 0 & 0 \\
\hline c.749T>C/- & $1(0.02)$ & 0 & 0 & 0 & 0 & 0 & 0 & 0 & 0 \\
\hline${ }^{\mathrm{a}} \mathrm{C} .1975 \mathrm{G}>\mathrm{C} / \mathrm{c} .919-2 \mathrm{~A}>\mathrm{G}$ & $2(0.04)$ & 0 & 0 & 0 & 0 & 0 & 0 & 0 & 0 \\
\hline${ }^{\mathrm{a}} \mathrm{C} .919-2 \mathrm{~A}>\mathrm{G} / \mathrm{c} .754 \mathrm{~T}>\mathrm{C}$ & 0 & $1(0.03)$ & 0 & 0 & 0 & 0 & 0 & 0 & 0 \\
\hline MT-RNR1 (NC_012920.1) & $10(0.2)$ & $5(0.1)$ & 0 & 0 & 0 & 0 & $1(7.1)$ & $1(16.7)$ & 0 \\
\hline m.1555A>G/- & $7(0.1)$ & $5(0.1)$ & 0 & 0 & 0 & 0 & $1(7.1)$ & $1(16.7)$ & 0 \\
\hline m.1494C>T/- & $2(0.04)$ & 0 & 0 & 0 & 0 & 0 & 0 & 0 & 0 \\
\hline${ }^{a} m .1555 A>G / m .1494 C>T$ & 1 (0.02) & 0 & 0 & 0 & 0 & 0 & 0 & 0 & 0 \\
\hline
\end{tabular}

${ }^{a}$ Compound heterozygote.

for Hereditary Deafness (China, ZeeSan, 802005) via the fluorescent PCR melting curve method. Limited genetic screening included genotyping 20 mutations in GJB2 (c.35delG, c.167delT, c.176_191del16, c.235delC, and c.299_300delAT), GJB3 (c.538C > T and c.547G>A), SLC26A4 (c.2168A>G, c.919$2 \mathrm{~A}>\mathrm{G}$, c. $1174 \mathrm{~A}>\mathrm{T}$, c. $1226 \mathrm{G}>\mathrm{A}$, c. $1229 \mathrm{C}>\mathrm{T}$, c. $1707+5 \mathrm{G}>\mathrm{A}$, c. $1975 \mathrm{G}>\mathrm{C}, \quad$ c. $2027 \mathrm{~T}>\mathrm{A}, \quad$ c.754T $>$ C, $\quad$ c.749T $>\mathrm{C}, \quad$ and c. $2162 \mathrm{C}>\mathrm{T}$ ), and MT-RNR1 (m.1494C $>\mathrm{T}$ and $\mathrm{m} .1555 \mathrm{~A}>\mathrm{G}$ ). According to the American College of Medical Genetics and Genomics and the Association for Molecular Pathology guidelines, all variants were pathogenic except for two variants in GJB3, which were classified as of uncertain clinical significance. All samples that presented any of the 20 screened mutations (positive) were confirmed by Sanger sequencing (provided by ZeeSan Biological Technology Co., Ltd, China). All homozygous and compound heterozygotes were asked to get the hearing diagnosis tests.

\section{Bioinformatics and Statistical Analysis}

Variants were named according to the sequence variant nomenclature recommended by the Human Genome Variation Society. The sequencing data were aligned to the Genome Reference Consortium Human Build 37 (GRCh37/hg19) using the Sequencher software (version 5.1). Statistical analysis was performed by using IBM
SPSS version 24.0 software (SPSS Inc., USA). Categorical variables are presented as frequencies and percentages ( $n$ [\%]). The chi-square test was used to compare differences in prevalence of screened mutations among ethnic groups. A two-tailed $p<0.05$ was considered statistically significant.

\section{RESULTS}

\section{Overall Hearing and Genetic Screening Results}

A total of 9,506 newborns (4,977 [52.4\%] males and 4,529 [47.6\%] females) underwent the concurrent hearing and genetic screening were included in this study. Among them, a total of $1,079(11.4 \%)$ newborns failed to pass the initial hearing screening, who referred to the re-screening at about 42 days age. Eventually, among $160(1.7 \%)$ infants that failed to pass the re-screening, 128 (1.4\%) infants presented the diagnostic hearing loss at about 3 months age. For genetic screening, $220(2.3 \%)$ newborns presented at least one of the 20 screened mutations. To explore the association between abnormal hearing screening outcomes with the presence of mutations, we analyzed the distribution of initial screening, rescreening, and diagnostic hearing loss among mutation positive 
TABLE 4 | Prevalence of hearing loss-associated mutations in this study, genomAD and ChinaMAP.

\begin{tabular}{|c|c|c|c|c|c|c|c|}
\hline \multirow[t]{2}{*}{ Mutation positive } & \multirow[t]{2}{*}{ This study } & \multicolumn{5}{|c|}{ gnomAD, \% } & \multirow[t]{2}{*}{ ChinaMAP } \\
\hline & & East Asian & South Asian & European (Non-finnish) & Ashkenazi Jewish & Latino & \\
\hline \multicolumn{8}{|c|}{ GJB2 (NM_004004.5) } \\
\hline c.235de1C & $80(0.8)$ & 0.7 & 0 & 0 & 0 & 0 & 0.8 \\
\hline c.299_300de1AT & $18(0.2)$ & 0.1 & 0 & 0 & 0 & 0 & 0.1 \\
\hline c.176_191del16 & $4(0.04)$ & 0.02 & 0 & 0 & 0 & 0 & No data \\
\hline \multicolumn{8}{|c|}{ GJB3 (NM_024009.3) } \\
\hline c. $538 \mathrm{C}>\mathrm{T}$ & $2(0.02)$ & 0.1 & 0 & 0 & 0 & 0 & 0.09 \\
\hline c. $547 \mathrm{G}>\mathrm{A}$ & $3(0.03)$ & 0.05 & 0 & 0 & 0 & 0.4 & 0.08 \\
\hline \multicolumn{8}{|c|}{ SLC26A4 (NM_000441.2) } \\
\hline c. $919-2 A>G$ & $49(0.5)$ & 0.5 & 0 & 0 & 0 & 0 & 0.6 \\
\hline c. $1229 \mathrm{C}>\mathrm{T}$ & $20(0.2)$ & 0.04 & 0.06 & 0.01 & 0.01 & 0.01 & 0.05 \\
\hline c.754T>C & $14(0.1)$ & 0.01 & 0 & 0 & 0 & 0 & 0.005 \\
\hline c. $1707+5 G>A$ & $4(0.04)$ & 0.01 & 0 & 0 & 0 & 0 & 0.005 \\
\hline c. 2168 A > G & $4(0.04)$ & 0.2 & 0 & 0 & 0 & 0 & 0.1 \\
\hline c. $1975 G>C$ & $5(0.04)$ & 0.02 & 0 & 0 & 0 & 0 & 0.04 \\
\hline c. $1174 \mathrm{~A}>\mathrm{T}$ & $3(0.03)$ & 0.01 & 0 & 0 & 0 & 0 & 0.01 \\
\hline c. $1226 \mathrm{G}>\mathrm{A}$ & $1(0.01)$ & 0.1 & 0.01 & 0.01 & 0 & 0.02 & 0.02 \\
\hline c. $2162 \mathrm{C}>\mathrm{T}$ & $1(0.01)$ & 0 & 0 & 0 & 0 & 0.03 & No data \\
\hline c.749T>C & $1(0.01)$ & No data & No data & No data & No data & No data & No data \\
\hline \multicolumn{8}{|c|}{ MT-RNR1 (NC_012920.1) } \\
\hline$m .1555 A>G$ & $15(0.2)$ & No data & No data & No data & No data & No data & No data \\
\hline m.1494C>T & $3(0.03)$ & No data & No data & No data & No data & No data & No data \\
\hline
\end{tabular}

and negative newborns. In comparison with mutation-negative newborns, those mutation positive newborns showed lower percentage of whom were able to pass the initial hearing screening $(p=0.018)$ and re-screening $(p=0.007)$, and higher prevalence of diagnostic hearing loss $(p=0.025)$, see Table 1.

\section{Characteristics of Different Ethnic Population}

Characteristics of the concurrent hearing and genetic screening in 22 different ethnic groups (the Han, Zhuang, Yao, Miao, Dong, Mulao, Hui, Maonan, Shui, Buyi, Tujia, Manchu, Mongolian, Bai, Gelao, Li, Yi, Dai, Jing, She, Naxi, and Korean) from Guangxi province are shown in Table 2. In this study, Han (5,265 [55.4\%]) group and Zhuang (3,464 [36.4\%]) group comprised the majority of newborns, while the other 20 ethnic groups (777 [8.2\%]) account for fewer than a tenth of the total population in this study.

We further analyzed detailed mutant genotypes in each ethnic group, and we did not identify any hearing lossassociated mutant homozygotes. Most of the mutation positive newborns are heterozygotes, and four of whom are compound heterozygotes including two newborns genotyped SLC26A4 c. $1975 \mathrm{G}>\mathrm{C} / \mathrm{c} .919-2 \mathrm{~A}>\mathrm{G}$, one newborn genotyped SLC26A4 c.919-2A $>\mathrm{G} / \mathrm{c} .754 \mathrm{~T}>\mathrm{C}$, and one newborn genotyped MT-RNR1 m.1555A $>$ G/m.1494C $>$ T (Table 3). To understand the hearing loss associated genetic epidemiology of population in this study, we listed the prevalence of those screened mutations in
East Asian, South Asian, European (Non-Finnish), Ashkenazi Jewish, and Latino ethnic populations according to the data from the Genome Aggregation Database (gnomAD) (21), and in a Chinese population according to the ChinaMAP (22). The prevalence of most screened mutations in this study is somehow inconsistent with the East Asian and South Asian ethnic populations or total Chinese population (Table 4). In comparison, the prevalence of SLC26A4 c.1229C > T and c.754T $>C$ seems to be higher, while the prevalence of $G J B 3$ c. $538 \mathrm{C}>\mathrm{T}$ and $\mathrm{c} .547 \mathrm{G}>\mathrm{A}$ seems to be lower in this study.

\section{Hearing Loss-Associated Mutations in Multiple Ethnic Populations}

Although the distribution of hearing loss-associated mutations seemed to be distinct between various ethnic groups (such as mutations on GJB2), the disparate number of populations of different ethnic groups might hamper the statistical comparison between majorities with minorities (Table 3). Thus, we further compared the differences of distribution of mutations only between Han group and Zhuang group (Table 5). Although no significant difference in the presence of any of the screened mutations was found between the two ethnic groups, some mutations such as GJB2 c.299_300de1AT $(p=0.087)$ and SLC26A4 c.1229C $>$ T $(p=0.063)$ have the tendency of distinguished prevalence between ethnic groups, which needs further study including larger number of subjects in the future. 
TABLE 5 | Comparison of hearing loss-associated mutations between Han and Zhuang groups.

\begin{tabular}{|c|c|c|c|c|c|c|}
\hline \multirow[t]{2}{*}{ Mutation positive, $n$ (\%) } & \multicolumn{2}{|c|}{ Han $(n=5,265)$} & \multicolumn{2}{|c|}{ Zhuang ( $n=3,464)$} & \multirow[t]{2}{*}{$\chi^{2}$} & \multirow[t]{2}{*}{$p$} \\
\hline & Positive & Negative & Positive & Negative & & \\
\hline Total & $130(2.5)$ & $5,135(97.5)$ & $72(2.1)$ & 3,392 (97.9) & 1.410 & 0.235 \\
\hline GJB2 (NM_004004.5) & $61(1.2)$ & 5,204 (98.8) & $29(0.8)$ & 3,435 (99.2) & 2.115 & 0.146 \\
\hline c.235de1C & $46(0.9)$ & $5,219(99.1)$ & $24(0.7)$ & 3,440 (99.3) & 0.859 & 0.354 \\
\hline c.299_300de1AT & $13(0.2)$ & $5,252(99.8)$ & $3(0.1)$ & 3,461 (99.9) & 2.935 & 0.087 \\
\hline c.176_191del16 & $2(0.04)$ & $5,263(99.96)$ & $2(0.06)$ & 3,462 (99.94) & $<0.001$ & 0.999 \\
\hline GJB3 (NM_024009.3) & $4(0.08)$ & $5,261(99.92)$ & $1(0.03)$ & $3,463(99.97)$ & 0.196 & 0.658 \\
\hline c.538C >T & $2(0.04)$ & $5,263(99.96)$ & 0 & $3,464(100)$ & 0.180 & 0.671 \\
\hline c. $547 \mathrm{G}>\mathrm{A}$ & $2(0.04)$ & $5,263(99.96)$ & $1(0.03)$ & $3,463(99.97)$ & $<0.001$ & 0.999 \\
\hline SLC26A4 (NM_000441.2) & $60(1.1)$ & 5,205 (98.9) & $37(1.1)$ & 3,427 (98.9) & 0.043 & 0.836 \\
\hline c. $919-2 A>G$ & $32(0.6)$ & $5,233(99.4)$ & $17(0.5)$ & 3,447 (99.5) & 0.513 & 0.474 \\
\hline c. $1229 \mathrm{C}>\mathrm{T}$ & $7(0.1)$ & 5,258 (99.9) & $11(0.3)$ & 3,453 (99.7) & 3.460 & 0.063 \\
\hline c. $754 \mathrm{~T}>\mathrm{C}$ & $6(0.1)$ & 5,259 (99.9) & $7(0.2)$ & $3,457(99.8)$ & 1.091 & 0.296 \\
\hline c. $1707+5 \mathrm{G}>\mathrm{A}$ & $4(0.08)$ & $5,261(99.92)$ & 0 & $3,464(100)$ & 1.235 & 0.266 \\
\hline c. 2168 A > G & $4(0.08)$ & $5,261(99.92)$ & 0 & $3,464(100)$ & 1.235 & 0.266 \\
\hline c. $1975 G>C$ & $4(0.08)$ & $5,261(99.92)$ & $2(0.06)$ & 3,462 (99.94) & $<0.001$ & 0.999 \\
\hline c. $1174 \mathrm{~A}>\mathrm{T}$ & $2(0.04)$ & $5,263(99.96)$ & $1(0.03)$ & $3,463(99.97)$ & $<0.001$ & 0.999 \\
\hline c. $1226 \mathrm{G}>\mathrm{A}$ & $1(0.02)$ & 5,264 (99.98) & 0 & $3,464(100)$ & $<0.001$ & 0.999 \\
\hline c. $2162 \mathrm{C}>\mathrm{T}$ & $1(0.02)$ & $5,264(99.98)$ & 0 & 3,464 (100) & $<0.001$ & 0.999 \\
\hline c.749T>C & $1(0.02)$ & $5,264(99.98)$ & 0 & $3,464(100)$ & $<0.001$ & 0.999 \\
\hline MT-RNR1 (NC_012920.1) & $10(0.2)$ & $5,255(99.8)$ & $5(0.1)$ & $3,459(99.9)$ & 0.253 & 0.615 \\
\hline m.1555A>G & $8(0.1)$ & $5,257(99.9)$ & $5(0.1)$ & $3,459(99.9)$ & 0.008 & 0.928 \\
\hline $\mathrm{m} .1494 \mathrm{C}>\mathrm{T}$ & $3(0.06)$ & 5,262 (99.94) & 0 & 3,464 (100) & 0.064 & 0.415 \\
\hline
\end{tabular}

\section{DISCUSSION}

In this study, we conducted the concurrent newborn hearing and genetic screening in 20 mutations in GJB2, GJB3, SLC26A4, and $M T-R N R 1$ for 9,506 normal newborns from 22 ethnic population in South China.

As a populous country with high incidence of birth defects including hearing loss (23), the national UNHS coverage rate showed an increment from 29.9 to $86.5 \%$ between 2008 and 2016 (24) in China. Although the UNHS has played an important role in early detection of congenital hearing loss $(7,10)$, there are still a proportion of hearing loss population that would be missed by using the conventional UNHS procedure, especially those mild, late-onset hearing loss newborns (3). In the past 10 years, genetic testing has been suggested as one of the most important etiological diagnostic methods for infants and children with hearing loss (25). So far, several large-scale concurrent hearing and genetic newborn screening programs have reported that using the limited genetic screening panel including even a small number of variants in genes commonly associated with hearing loss (GJB2, GJB3, SLC26A4, and MT-RNR1) could improve the effectiveness of elucidating etiologies, informing high-risk newborns and their maternal relatives of hearing loss $(26,27)$.

In our results, the total positive rate of limited genetic screened mutations was $2.3 \%$, which was within the comparable range of positive rates in previous studies $(18,28)$. However, the positive rates of same mutations ranged widely from about 1.5 to $5 \%$ (29), indicating the considerable disparity of hearing loss-associated genetic epidemiology in different regions in China. Besides, we observed the potential association between mutant heterozygotes with abnormal hearing screening outcomes, which was always ignored from analysis in previous studies, since the limited genetic screened mutations are regarded as recessive pathogenic or drug susceptible mutations. In addition, the screening panel included only 20 mutations, which could not account for all possible genetic factors associated with hearing loss in this study. It needs further studies to identify if any other risk factors influence the newborn hearing screening outcomes.

It is known that the carrier frequencies of Mendelian disorders, including genetic-associated hearing loss, could be considerably different between various ethnic groups (30). Although there were numerous hearing and genetic screening studies conducted in different regions in China during the past years, few studies focus on the disparity of hearing loss-associated genetic epidemiology in different ethnic groups $(20,28,31)$. A recent study indicated the variable population-specific allelic spectra of known hearing loss-associated pathogenic variants using data from 123,136 individuals in seven different ethnic groups (13). To our knowledge, this is the first study that demonstrated the characteristics and distribution of hearing and genetic screening results in a large-scale multiple ethnic population in South China. Although there are no significant differences between the two main ethnic groups in this study, two mutations have the tendency of distinguished distribution 
in different ethnic groups. In addition, we have reported the prevalence of SLC26A4 c.2162C > T and c.749T >C in a South Chinese population, which were absent in the ChinaMAP. Since the sample size of some minority ethnic population was too small for comparative analysis, studies including more minority ethnic populations are needed.

In general, these multi-ethnic population characteristics of Guangxi province provide us a good opportunity to explore genomic contributions to hearing loss that vary by different ethnic populations and to promote the application of this knowledge to clinical care in the future (32).

\section{CONCLUSIONS}

In this concurrent newborn hearing and genetic screening in a large-scale and multiple ethnic population in South China, we find that newborns who had at least one hearing loss-associated mutation are more likely to fail the hearing screening and have diagnostic hearing loss. However, we did not identify any significant difference in the prevalence of screened mutations between the majority Han ethnic group and Zhuang group, despite the lack of number of minority ethnic groups.

\section{DATA AVAILABILITY STATEMENT}

The original contributions presented in the study are included in the article/supplementary material, further inquiries can be directed to the corresponding author/s.

\section{REFERENCES}

1. Roland L, Fischer C, Tran K, Rachakonda T, Kallogjeri D, Lieu JE. Quality of Life in Children with hearing impairment: systematic review and meta-analysis. Otolaryngol Head Neck Surg. (2016) 155:208-19. doi: 10.1177/0194599816640485

2. Kremer H. Hereditary hearing loss; about the known and the unknown. Hear Res. (2019) 376:58-68. doi: 10.1016/j.heares.2019.01.003

3. Alford RL, Arnos KS, Fox M, Lin JW, Palmer CG, Pandya A, et al. American College of Medical Genetics and Genomics guideline for the clinical evaluation and etiologic diagnosis of hearing loss. Genet Med. (2014) 16:34755. doi: 10.1038/gim.2014.2

4. Distefano MT, Hemphill SE, Oza AM, Siegert RK, Grant AR, Hughes MY, et al. ClinGen expert clinical validity curation of 164 hearing loss gene-disease pairs. Genet Med. (2019) 21:2239-47. doi: 10.1038/s41436-019-0487-0

5. Azaiez H, Booth KT, Ephraim SS, Crone B, Black-Ziegelbein EA, Marini RJ, et al. Genomic landscape and mutational signatures of deafness-associated genes. Am J Hum Genet. (2018) 103:484-97. doi: 10.1016/j.ajhg.2018.08.006

6. Lieu JEC, Kenna M, Anne S, Davidson L. Hearing loss in children: a review. JAMA. (2020) 324:2195-205. doi: 10.1001/jama.2020.17647

7. Wroblewska-Seniuk KE, Dabrowski P, Szyfter W, Mazela J. Universal newborn hearing screening: methods and results, obstacles, and benefits. Pediatr Res. (2017) 81:415-22. doi: 10.1038/pr.2016.250

8. Kamenov K, Chadha S. Methodological quality of clinical guidelines for universal newborn hearing screening. Dev Med Child Neurol. (2021) 63:1621. doi: $10.1111 / \mathrm{dmcn} .14694$

9. Sheng H, Zhou Q, Wang Q, Yu Y, Liu L, Liang M, et al. Comparison of two-step transient evoked otoacoustic emissions and one-step automated auditory brainstem response for universal newborn hearing screening programs in remote areas of China. Front Pediatr. (2021) 9:655625. doi: 10.3389/fped.2021.655625

\section{ETHICS STATEMENT}

The studies involving human participants were reviewed and approved by the Ethics Committee of Liuzhou Maternal and Child Health Care Hospital. Written informed consent to participate in this study was provided by the participants' legal guardian/next of kin.

\section{AUTHOR CONTRIBUTIONS}

XT, TY, and JC contributed to conception and design of the study. LL, SLi, ML, and TL collected the data. XT and SLu performed the genetic and statistical analysis. XT and TY wrote the first draft of the manuscript. JC refined the draft of the manuscript. All authors contributed to manuscript revision, read, and approved the submitted version.

\section{FUNDING}

This study was supported by grant Z20180014 to XT from the Guangxi Medicine and Health Self-financing Research Project.

\section{ACKNOWLEDGMENTS}

We thank all the subjects and their parents for their participation. We thank Dr. Qixuan Wang and Prof. Zhiwu Huang from Shanghai Ninth People's Hospital, Shanghai Jiao Tong University School of Medicine for their assistance in statistical analysis.

10. Morton CC, Nance WE. Newborn hearing screening - a silent revolution. $N$ Engl J Med. (2006) 354:2151-64. doi: 10.1056/NEJMra050700

11. Wu CC, Tsai CH, Hung CC, Lin YH, Lin YH, Huang FL, et al. Newborn genetic screening for hearing impairment: a population-based longitudinal study. Genet Med. (2017) 19:6-12. doi: 10.1038/gim.2016.66

12. Wojcik GL, Graff M, Nishimura KK, Tao R, Haessler J, Gignoux CR, et al. Genetic analyses of diverse populations improves discovery for complex traits. Nature. (2019) 570:514-8. doi: 10.1038/s41586-019-1310-4

13. Chakchouk I, Zhang D, Zhang Z, Francioli LC, Santos-Cortez RLP, Schrauwen I, et al. Disparities in discovery of pathogenic variants for autosomal recessive non-syndromic hearing impairment by ancestry. Eur J Hum Genet. (2019) 27:1456-65. doi: 10.1038/s41431-019-0417-2

14. Mcdermott JH, Molina-Ramírez LP, Bruce IA, Mahaveer A, Turner M, Miele $\mathrm{G}$, et al. Diagnosing and preventing hearing loss in the genomic age. Trends Hear. (2019) 23:2331216519878983. doi: 10.1177/2331216519878983

15. Tsukada K, Nishio SY, Hattori M, Usami S. Ethnic-specific spectrum of GJB2 and SLC26A4 mutations: their origin and a literature review. Ann Otol Rhinol Laryngol. (2015) 124(Suppl. 1):61-76s. doi: 10.1177/0003489415575060

16. Zhang HG, Chen YF, Ding M, Jin L, Case DT, Jiao YP, et al. Dermatoglyphics from all Chinese ethnic groups reveal geographic patterning. PLoS ONE. (2010) 5:e8783. doi: 10.1371/journal.pone.0008783

17. Kong QP, Sun C, Wang HW, Zhao M, Wang WZ, Zhong L, et al. Largescale mtDNA screening reveals a surprising matrilineal complexity in east Asia and its implications to the peopling of the region. Mol Biol Evol. (2011) 28:513-22. doi: 10.1093/molbev/msq219

18. Zhang Z, Ding W, Liu X, Xu B, Du W, Nan S, et al. Auditory screening concurrent deafness predisposing genes screening in 10,043 neonates in Gansu province, China. Int J Pediatr Otorhinolaryngol. (2012) 76:9848. doi: 10.1016/j.ijporl.2012.03.016

19. Zhang J, Wang P, Han B, Ding Y, Pan L, Zou J, et al. Newborn hearing concurrent genetic screening for hearing impairment-a clinical practice in 
58,397 neonates in Tianjin, China. Int J Pediatr Otorhinolaryngol. (2013) 77:1929-35. doi: 10.1016/j.ijporl.2013.08.038

20. Hao Z, Fu D, Ming Y, Yang J, Huang Q, Lin W, et al. Large scale newborn deafness genetic screening of 142,417 neonates in Wuhan, China. PLoS ONE. (2018) 13:e0195740. doi: 10.1371/journal.pone.0195740

21. Karczewski KJ, Francioli LC, Tiao G, Cummings BB, Alföldi J, Wang Q, et al. The mutational constraint spectrum quantified from variation in 141,456 humans. Nature. (2020) 581:434-43. doi: 10.1038/s41586-020-2308-7

22. Cao Y, Li L, Xu M, Feng Z, Sun X, Lu J, et al. The ChinaMAP analytics of deep whole genome sequences in 10,588 individuals. Cell Res. (2020) 30:717-31. doi: 10.1038/s41422-020-0322-9

23. Dai L, Zhu J, Liang J, Wang YP, Wang H, Mao M. Birth defects surveillance in China. World J Pediatr. (2011) 7:302-10. doi: 10.1007/s12519-01 1-0326-0

24. Yuan X, Deng K, Zhu J, Xiang L, Yao Y, Li Q, et al. Newborn hearing screening coverage and detection rates of hearing impairment across China from 20082016. BMC Pediatr. (2020) 20:360. doi: 10.1186/s12887-020-02257-9

25. Shearer AE, Shen J, Amr S, Morton CC, Smith RJ. A proposal for comprehensive newborn hearing screening to improve identification of deaf and hard-of-hearing children. Genet Med. (2019) 21:261430. doi: 10.1038/s41436-019-0563-5

26. Dai P, Huang LH, Wang GJ, Gao X, Qu CY, Chen XW, et al. Concurrent Hearing and Genetic Screening of 180,469 Neonates with Follow-up in Beijing, China. Am J Hum Genet. (2019) 105:803-12. doi: 10.1016/j.ajhg.2019.09.003

27. Wang Q, Xiang J, Sun J, Yang Y, Guan J, Wang D, et al. Nationwide population genetic screening improves outcomes of newborn screening for hearing loss in China. Genet Med. (2019) 21:2231-8. doi: 10.1038/s41436-019-0481-6

28. Peng Q, Huang S, Liang Y, Ma K, Li S, Yang L, et al. Concurrent genetic and standard screening for hearing impairment in 9317 southern Chinese Newborns. Genet Test Mol Biomarkers. (2016) 20:603-8. doi: 10.1089/gtmb.2016.0055
29. He X, Li X, Guo Y, Zhao Y, Dong H, Dong J, et al. newborn screening of genetic mutations in common deafness genes with bloodspot-based gene chip array. Am J Audiol. (2018) 27:57-66. doi: 10.1044/2017_AJA-17-0042

30. Lazarin GA, Haque IS, Nazareth S, Iori K, Patterson AS, Jacobson JL, et al. An empirical estimate of carrier frequencies for $400+$ causal Mendelian variants: results from an ethnically diverse clinical sample of 23,453 individuals. Genet Med. (2013) 15:178-86. doi: 10.1038/gim.2012.114

31. Fu Y, Zha S, Lü N, Xu H, Zhang X, Shi W, et al. Carrier frequencies of hearing loss variants in newborns of China: a meta-analysis. J Evid Based Med. (2019) 12:40-50. doi: 10.1111/jebm.12305

32. Hindorff LA, Bonham VL, Brody LC, Ginoza MEC, Hutter CM, Manolio TA, et al. Prioritizing diversity in human genomics research. Nat Rev Genet. (2018) 19:175-85. doi: 10.1038/nrg.2017.89

Conflict of Interest: The authors declare that the research was conducted in the absence of any commercial or financial relationships that could be construed as a potential conflict of interest.

Publisher's Note: All claims expressed in this article are solely those of the authors and do not necessarily represent those of their affiliated organizations, or those of the publisher, the editors and the reviewers. Any product that may be evaluated in this article, or claim that may be made by its manufacturer, is not guaranteed or endorsed by the publisher.

Copyright (c) 2021 Tang, Liu, Liang, Liang, Liao, Luo, Yan and Chen. This is an open-access article distributed under the terms of the Creative Commons Attribution License (CC BY). The use, distribution or reproduction in other forums is permitted, provided the original author(s) and the copyright owner(s) are credited and that the original publication in this journal is cited, in accordance with accepted academic practice. No use, distribution or reproduction is permitted which does not comply with these terms. 